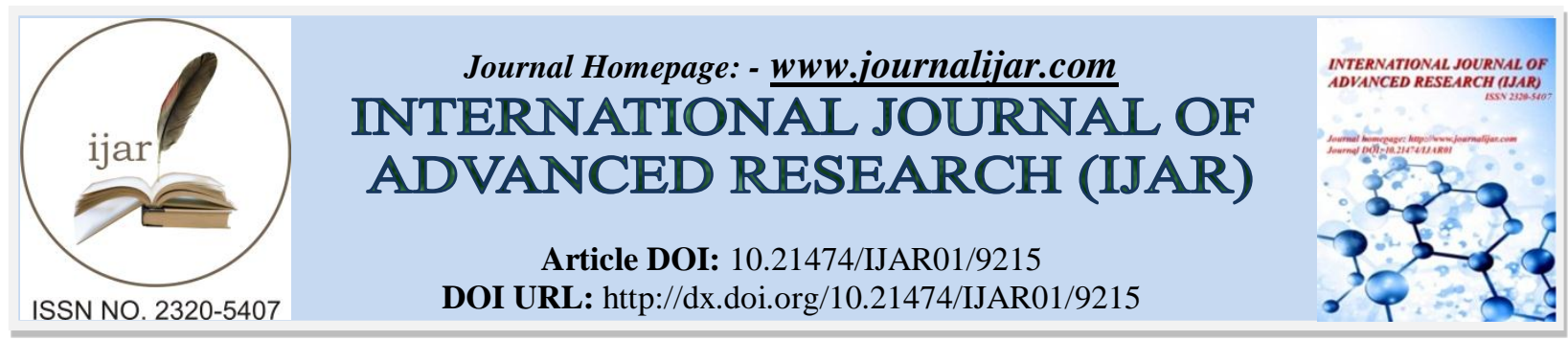

RESEARCH ARTICLE

\title{
IDIOPATHIC CARPAL TUNNEL SUNDROME ( I.C.T.S.) CLINICAL AND ELECTROPHYSIOLOGICAL EVALUATION IN IRAQI PATIENTS.
}

\author{
Dr. wijdan H. AL- Shami. \\ M.B.Ch.B, DR /DMR Specialist Doctor in Rheumatology and Rehabilitation Al- Yarmouk TeachingHospital, Iraq / \\ Baghdad.
}

\section{Manuscript Info}

Manuscript History

Received: 05 April 2019

Final Accepted: 07 May 2019

Published: June 2019

\section{Abstract}

Introduction: carpal tunnel syndrome ( C.T.S )is a world wide disease which affects $5-10 \%$ of population with a variable distribution rate among persons depending on their sex, age, occupation and precipitating factors ( in secondary C.T.S ) .It usually affects adults, females more than males It has variable modes of presentation and variable ways of alleviating the symptoms .

This study aimed at evaluation of I.C.T.S both clinically and electrophysiologicaly in Iraqi patients .

Patients and Methods : 54 Iraqi patients with 77 hands affected by I.C.T.S ( Secondary C.T.S cases were excluded )were received in rheumatology consultation clinic /AL- Yarmouk Teaching Hospital /Baghdad along 4 months period, and were evaluated (thouroghly )regarding age , sex , occupation, clinical , and electro-phys. abnormalities . Results were compared with other studies from other populations .

Results : most of our patients were middle age - females doing heavy house - wife activities with chief presenting complaint of hyperesthesia.Clinically less wasting but more weakness than in other studies Electro-phys, results were comparable to other studies regarding DML and SAP but with a lower incidence of spontaneous activity among our pts.

Conclusion : I.C.T.S . / Iraqi pts.is widely comparable to other studies ( from different parts of the world ) a part from less wasting of thenar muscles and lower $\%$ of spontaneous activity in electro - phys .study.

Copy Right, IJAR, 2019,. All rights reserved.

\section{Introduction:-}

C.T.S. ia an enterapment neuropathy at the wrist It can be primary ( idiopathic)= (I.C.T.S.) or secondary due to different causes. Clinically both types are the same. The main presenting symptoms are pain, numbness and tingling in the median nerve territory ( thumb, index, middle finger + half of the ring finger)in the hand . They typically start gradually and during the night, pain may extend up the arm. Weak grip strength may occur late in disease .

Thenar muscles may waste away in $<50 \%$ of patients with chronic C.T.S $2,3,4,5,6,7,8$

In many pts.C.T.S is Bilateral ${ }^{9}$.The syndrome is diagnosed by : symptoms, specific physical tests ( Phalen .Tinel ), electrodiagnostic study and musculo - skeletal ultrasound (m-sk U/S) ${ }^{1,10,11,13,15,16,17,20}$. 


\section{Patients and Methods :}

54 pts ( with 77 affected hands ) presented to our consulation clinic along 4 months period with symptoms suggestive of C.T.S

All pts. were evaluated clinically by :

Phalens tests, Tinels test, pin prick sensation ( comparing Median nerve supplied area with tip of little finger ), wasting of thenar muscles and power examination for both abductor pollicis brevis (A.P.B.) and Opponens pollicis (Op.P.).All cases of secondary C.T.S .were excluded (pregnancy, contraceptive pills , D.M., acromegaly, hypothyroidism, trauma, OA changes, inflammatory dis. (like R.A) ,P.N.P and M.N.M ) by questioning , and different lab tests ( $\mathrm{CBC}+\mathrm{ESR}$, F.B.S . thyroid function test etc). X- Ray and $\mathrm{m}-\mathrm{sk} \mathrm{U} / \mathrm{S}$ of the wrist were done to exclude traumatic causes (e.g lunate fracture )and osteoarthritic changes .

Each pt.was questioned about :

1-Duration of sympts ., distribution area ,severity of sympts (by visual analog scale : V.A.S.)

2-Detailed questionnaire about different presenting symps. Including : tightness, puffiness, clumsiness and paresthesia .

3-What relieves the pts sympts .

Lastly pts, were subjected to ENG /EMG study for both median and ulnar nerves in each affected hand : DML , NCV , SAP-L and SAP- Amp. for median $n$ while only SAP-L and SAP-Amp for ulnar $n$. ( to exclude any possibility of P.N.P.)

C.T.S was diagnosed if :

1 -DML $<4.1 \mathrm{~m} \mathrm{sec}$

2-SAP - Latency $<3.7 \mathrm{msec}$ ( using surface ring electrodes )

3.SAP- Amp /median n : SAP-Amp /ulnar n. => 1

\section{Results:-}

54 pts. :31 with Unilat C.T.S ( affecting the dominant hand) and 23 with Bilat C.T .S.

Analysis of our total77 hands with I.C.T.S showed :

Table 1 : According to sex ,age, occupation

Sex distribution $94 \%$ Female $6 \%$ Male

Age 23-60 years ( mean age 38 years )

Occupation :

\begin{tabular}{|l|l|}
\hline House wife & $76 \%$ \\
\hline Teacher & $9.2 \%$ \\
\hline Clerk & $5.5 \%$ \\
\hline Labourer & $5.5 \%$ \\
\hline farmer & $1.9 \%$ \\
\hline
\end{tabular}

Table 2 : Presenting sympts

\begin{tabular}{|l|l|}
\hline Tingling & $85.7 \%$ \\
\hline Tightness & $90.9 \%$ \\
\hline Numbness & $100 \%$ \\
\hline Soreness & $90.9 \%$ \\
\hline Burning & $40 \%$ \\
\hline Puffiness & $57 \%$ \\
\hline Coldness & $15.6 \%$ \\
\hline Clumsiness & $66 \%$ \\
\hline Nucturnal worsening & $84.4 \%$ \\
\hline Proximal referral & $80.5 \%$ \\
\hline
\end{tabular}


Table 3: According to signs / physical exam.

\begin{tabular}{|l|}
\hline ve phalens test found in $74+\%$ \\
\hline ve Tinels test found in $80.5 \%+\%$ \\
\hline Hypoesthesia found in $46.8 \%$ \\
\hline Hyperesthesia found in $14.2 \%$ \\
\hline Wasting found in $6.9 \%$ \\
\hline Weakness found in $62.3 \%$ \\
\hline
\end{tabular}

Table 4: sympts were relieved by:

\begin{tabular}{|l|l|}
\hline Hanging hands down & $50 \%$ \\
\hline Massage & $85 \%$ \\
\hline Execiese & $83.3 \%$ \\
\hline Shaking & $68.5 \%$ \\
\hline Slapping & $18.5 \%$ \\
\hline Immersing / hot water & $13 \%$ \\
\hline Putting on cold surface & $3.7 \%$ \\
\hline Elevation of hand & $3.7 \%$ \\
\hline bandaging & $3.7 \%$ \\
\hline
\end{tabular}

Table 5: Symptomes distributions / Hands

\begin{tabular}{|l|c|}
\hline Whole hand & $48 \%$ \\
\hline Index middle finger & $27 \%$ \\
\hline Only middle finger & $.10 .3 \%$ \\
\hline Median n distrib & $9 \%$ \\
\hline Middle and ring finger & $5 \%$ \\
\hline
\end{tabular}

Table 6: Frequency of electrophysiological abn.

\begin{tabular}{|l|l|}
\hline .Spont.act & $9 \%$ \\
\hline Prolonged DML & $79 \%$ \\
\hline L-Prolonged SAP & $91 \%$ \\
\hline Amp-Decreased SAP & $41.5 \%$ \\
\hline not obtained -SAP & $9 \%$ \\
\hline
\end{tabular}

Table 7 : According to severity of sympts

\begin{tabular}{|l|l|}
\hline Duration $<1$ y & $62 \%$ \\
\hline V.A.S $<5$ & $62 \%$ \\
\hline (grade 4 ) Weakness & $61 \%$ \\
\hline (. Wasting ( thenar $\mathrm{m}$ & $16.8 \%$ \\
\hline DML $<6$ mesc & $16.8 \%$ \\
\hline L $<5.7$ msec - SAP & $18 \%$ \\
\hline Spont.act + ve & $9 \%$ \\
\hline
\end{tabular}

Comparison of our 77 I.C.T.S cases with other studies :

Table1 :According to sex, age, bilaterality and occupation

\begin{tabular}{|l|l|l|l|l|}
\hline & Our study & ${ }^{23}$ Phalens & ${ }^{8}$ Philip L.H & ${ }^{9}$ Bendles \\
\hline sex & female \% 94 & female $\% 67$ & $\begin{array}{l}\text { Female : male } \\
10-2\end{array}$ & \\
\hline Age & y $60-23$ & y $87-20$ & y $50-30$ & $\% 33$ \\
\hline Bilateral & $\% 43$ & ----- & $\% 33$ & $\begin{array}{l}\text { clinically \%33 } \\
\text { EMG \% 61 }\end{array}$ \\
\hline Occupation & $\% 76$ & $\% 50$ & & \\
\hline House wife & $\% 9.2$ & $\% 2$ & \\
\hline Teacher & $\% 5.5$ & $\% 3.6$ & & \\
\hline Clerk & &
\end{tabular}




\begin{tabular}{|l|l|l|l|l|}
\hline Labourer & $\% 5.5$ & $\% 5.9$ & & \\
\hline Farmer & $\% 1.9$ & $\% 0.9$ & & \\
\hline Others & $\ldots .$. & $\% 40$ & & \\
\hline
\end{tabular}

Table 2: comparing signs and sympts:

\begin{tabular}{|l|l|l|l|l|l|}
\hline & Our study & ${ }^{23}$ Phalens & ${ }^{24}$ Richard & ${ }^{10}$ Gellman & ${ }^{11}$ Golding \\
\hline Phalen's test & $\% 74$ & $\% 80-\% 74$ & $\% 66$ & $\% 71$ & $\% 77$ \\
\hline Tinel's test & $\% 80.5$ & $\% 73$ & $\% 74$ & $\% 44$ & $\% 66$ \\
\hline Loss of sens & ---- & $\% 92$ & ----- & ------ & ----- \\
\hline Hypoesthesia & $\% 46.8$ & $\% 79$ & ----- & ------ & $\% 72$ \\
\hline Hyperesthseia & $\% 14.2$ & $\% 4.6$ & ----- & ------ & ------ \\
\hline Paresthesia & ----- & $\% 6$ & ------ & ------ & ------ \\
\hline Wasting & $\% 7$ & $\% 41$ & $\% 36$ & ------ & ------ \\
\hline weakness & $\% 62.3$ & ----- & $\% 44$ & ------ & ----- \\
\hline
\end{tabular}

Table 3: comparing electro - phys.abn.

\begin{tabular}{|c|c|c|c|c|c|c|c|}
\hline & $\begin{array}{l}\text { Our } \\
\text { study }\end{array}$ & ${ }^{14}$ Ani -F.Al & ${ }^{12}$ Kelly & ${ }^{28}$ Titey & ${ }^{24}$ Richard & ${ }^{26}$ Kopell & ${ }^{19}$ Gelhmen \\
\hline .Spont act & $\% 9$ & $\% 16.3$ & $\% 50$ & $\% 46$ & $\% 48$ & $\% 40$ & --- \\
\hline $\mathrm{DML}<6 \mathrm{msec}$ & $\% 16.8$ & ----- & ----- & $\% 16$ & ---- & ----- & $\begin{array}{ll}--- \\
\end{array}$ \\
\hline $\mathrm{SAP}<5.7 \mathrm{msec}$ & $\% 18$ & ----- & ----- & ----- & $\% 16$ & ----- & ----- \\
\hline Abn.DML & $\% 79$ & $\% 76.7$ & $\% 70$ & ---- & $\% 2$ & $\% 84$ & $\% 94$ \\
\hline Abn.SAP & $\% 91$ & $\% 86$ & ----- & $\% 85$ & $\% 90$ & $\% 95$ & $\% 88$ \\
\hline
\end{tabular}

\section{Discussion and Conclusion:-}

In our 77 I.C.T.S hands we noticed :

Most of them were middle age females (house - wives ) using their hands excessively (this goes with the effect of heavy manual work as a cause of (I.C.T.S ). ${ }^{21,22}$

According to sympts : numbness was the main presenting sympt in all pts., Followed by tightness , soreness , tingling and puffiness of the hand .Burning sens. $44 \%$ was much higher than coldness $15.6 \%$. Nocturnal worsening was found in $84.4 \%$ of pts. Clumsiness was noticed in $<50 \%$ of pts $(66 \%)$ and proximal referral showed a high $\%(80.5 \%)$. A +ve phalen test found in $74 \%$ which was comparable to other studies while +ve Tinel's test ( $80 \%$ ) was higher than them , $61 \%$ of pts. reported sensory changes in the form of hypo or hyperalgesia and we noticed that there were more pts with hyperesthesia in our study than in Phalens ${ }^{23}$.

Less wasting was noticed in our pts inspite of long duration of disease and severe compression of the $\mathrm{n}$, but high $\%$ of weakness ( Grade IV)was reported 10,11,23,24 Spont .act.was low in our pts, when compared to others while Dr.F.AlAni in his study in Iraq at 1989 put a $\%$ of $16.3 \%{ }^{14}$ which is very near to ours Johnson reported spont .act.as very rare ${ }^{12}$ DML and SAP abnormalities were recoded in $79 \%$ and $91 \%$ respectively and were comparable to other studies $10,12,14,24,26,28$ 


\section{REFERENCE:-}

1. Burton ,C; Chesterton ,LS ; Daven port ,G (may 2014): "Diagnosing \&managing C.T.S .in primary care" The British Journal of General practice

2. C.T.S. fact sheet: National institute of neurological disorders and stroke (jan. 28,2016)

3. Padual , : L; Coraci,D; Erra,C; : " C.T.S. : clinical features, diagnosis \& management " Lancet neurology (review). 15 (12): 1273-84

4. Beringer U .Neurolklin univ. Bern : "carpal tunnle syndrome" Schueizmed usher 102/2 (52-85) 1972

5. Bickel .KD (Jan. 2010) :Carpal tunnel syndrome"'The Journal of surgery 35(1):147-52

6. Katz, Jeffrey N. ; Simmons. Barry P. (2002) : Carpal tunnle syndrome" New England Journal of medicine 346(23)1807-12

7. Ibrahim I. Khan W.S ,Goddard N (2012) :"C.T.S. : a Review of the recent Literatures" The open orthopedics Journal 6: 69-76

8. Philip L. Heywood G.P, Leeds LS TAX:".Through the carpal tunnel". BMJ., vol 294 ,(14 manch 1987)

9. Bendles EM. GreenspurB/Dept. phys. Med. Rehab. Univ. Pennsylvania Philadelphia USA.:"The Bilaterality of C.T.S." Arch phys med. Red. Reh. 58/8 (362-364)(1977)

10. Haris Gellman M.D/ Los Angeles Richand H. Gelberman M.D/ San Diego California, Division of Orthopeadic and Rehab. University of California at San Diego Med. Center."C.T.S. an evaluation of provocative diagnostic tests"Journal of bone \& joint surgery vol. 68-A (june 1986)

11. Golding D.M. Rose and K.Selvarajah /west essex. Rheumatology unit, Princess Alexandra hospital :"clinical practice , clinical tests for C.T.S. an evaluation " British jounal of Rheumatology 25 (388-390)1986

12. William and Kelley M.D. Edward D.Harris J.R.M.D. :" Carpal Tunnel syndrome" Text book of Rheumatology 1981 Kelley \& Firestein text book $9^{\text {th }}$ Ed. 2013

13. Robert M Szabo MD. , Richard H. Gelberman M.D. /San Diago California university hospital :" Sensibility testing in patients with C.T.S." The Journal of bone \& Joint surgery vol 66-A (Jan 1984)

14. Fakher AL.Ani/ Dept. of Clinical physiology Saddam college of Med- Baghdad. :"Electromygraphic and N.C.V. studies in patients with C.T.S". Paper from the 5th National Medical congress of college of medicine university of Baghdad( 1989)

15. Graham, B. ( 1 December 2008 )":The value added by electrodiagnostic testing in the diagnosis of C.T.S." The journal of Bone \&joint surgery 90(12) 2587-93

16. Stevens JC AAEE minimograph ":The electro diagnosis of C.T.S." American Association of electro diagnostic medicine muscle nerve 1997; 20: 1477-86

17. Padua L, Lo Monaco M, Valente EM.": A useful electrophysiological parameter for diagnosing of C.T.S. " Muscle L, Nerve( 1996) $19: 48-53$

18. American Association of electrodiagnostic medicine /American Academy of neurology American Academy of physical medicine and Rehab " Practice parameter for electrdiagnostic studies in C.T.S. : summary statement "Muscle Nerve. (2002) ; 25 :918-22

19. Keivin Basiri \&Bashar Katirgi .: "Practical approach to electro diagnosis of the C.T.S. A review" Advanced Biomedical research . (2015) ; 4:50

20. Wolters Kluwer - Medknow publications Robinson .L (2007) ) "Electro diagnosis of C.T.S". Physical Medicin and Rehabilitation of North America 18(4):733-46

21. Werner ,Robert A (2006)"Evaluation of work-related C.T.S." Journal of occupational rehab. 16(2):201-16

22. Luckhaupt SE, Dahlhamer JM.Ward BW ( june 2013 )" Prevalence and work relatedness of C.T.S . in the working population ." American journal of international medicine 56 (6): 615-24

23. Phalen G.S. :The C.T.S 17 year experience in diagnosis and treatment of 646 hands" Journal bone and joint surg. 48A (211-228)(1966)

24. Richard H.Gelberman M.D .David Aronson M.D/ . Divisions of orthop surg.and rheumatology/ university of californium at SanDiego . "C.T.S results of prospective trial of steroid injection and splinting." The Journal of bone and joint surg . 62-A no,70 (1181-84)( Oct.(1980) .

25. Deckers H. vanstenland H.: " E MG finding in C.T.S " Rheumatol .Med.Phy.23/6 ( 269-80 )(1970)

26. Kopell H.P. Goodgold J ./Clin orthosurg. New york univ.sch.of med.New York ":Clinical and EMG features of C.T.S " Arch.phys.Med 49/7 ( 371-75) (1968)

27. Titze A.Urfallkarankenh :"The C.T.S a conduction velocity frequently overlooked Grz-Chir praxis 18/3 ( 497 504)(1974)" 